\title{
Cancers Potentially Preventable through Excess Weight Reduction in Germany in 2010
}

\author{
Antje Wienecke ${ }^{a} \quad$ Hannelore Neuhauser $^{b} \quad$ Klaus Kraywinkel $^{a}$ \\ Benjamin Barnes ${ }^{a}$ \\ a German Centre for Cancer Registry Data, Department of Epidemiology and Health

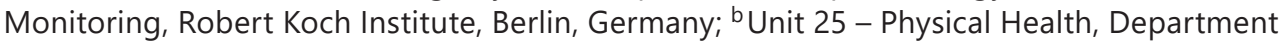 \\ of Epidemiology and Health Monitoring, Robert Koch Institute, Berlin, Germany
}

\section{Keywords}

Overweight · Obesity · Cancer incidence $\cdot$ Population-attributable risk · Germany

\begin{abstract}
Objective: In order to quantify the preventive potential of body weight reduction in Germany, population-attributable risks (PARs) were estimated for 13 cancer types. Methods: PARs were calculated using body weight prevalence from a nationwide survey from 1998, cancer incidence estimates for 2010 from cancer registry data and relative risk estimates from published meta-analyses. Three counterfactual scenarios were evaluated: reducing BMI to maximally 21 $\mathrm{kg} / \mathrm{m}^{2}$ (main analysis) and weight reductions among overweight and obese persons of $5 \%$ and 10\%. Results: An estimated 9\% of all incident cancer cases in Germany - 40,748 cases - could be attributed to excess body weight in 2010. The highest proportions were estimated for endometrial cancer (48\%) and oesophageal adenocarcinoma (48\% for women, $46 \%$ for men). The largest case numbers were estimated for postmenopausal breast (9,081 cases), colorectal (8,002 cases among men, 3,297 cases among women) and endometrial cancer (5,468 cases). The additional counterfactual scenarios suggested that weight reductions of $5 \%$ and $10 \%$ could prevent 5,572 cases and 11,427 cases, respectively. Conclusions: In Germany there is a considerable preventive potential for cancers associated with excess body weight. Efforts to prevent further weight gain and encourage weight loss should be promoted.
\end{abstract}

(C) 2018 The Author(s)

Published by S. Karger GmbH, Freiburg 
Wienecke et al.: Cancers Potentially Preventable through Excess Weight Reduction in Germany in 2010

\section{Introduction}

Excess body weight is associated with many types of cancer [1-3] as well as with other diseases such as type 2 diabetes, hypertension and cardiovascular diseases [4-6]. Regarding its etiologic role in carcinogenesis, it has been hypothesized that excess body weight may act through various pathways: increased lipids and lipid signalling, heightened inflammatory responses, insulin resistance and adipokine dysregulation [7, 8].

In Europe, country-level self-reported obesity prevalence varies greatly, ranging from 9 to $23 \%$ among women and 9 to $27 \%$ among men, with the prevalence in Germany lying slightly above the European average [10]. A nationwide survey of German adults with measured height and weight (which tend to yield higher BMI than self-reports [11]) indicated that $60 \%$ of German adults were at least overweight and that $23 \%$ were obese [12].

The proportion of overweight and obese people worldwide has increased over recent decades [13], and increasing trends can be observed across Europe and in Germany as well [14].

Meanwhile, the prevalence of other important cancer risk factors, in particular tobacco and alcohol consumption, has decreased in European countries [14-16]. Given these trends, the relative burden of overweight- and obesity-associated cancers is likely to rise [17].

To address differences both in risk factor prevalence and temporal trends in prevalence it is important to perform country-specific analyses of disease burden. Up to now, only one study has estimated the health burden and costs attributable to overweight/obesity for Germany, using German BMI prevalence data and relative risks derived from a large US study [18]. This study considered various diseases related to excess body weight and focused on cancer mortality instead of cancer incidence, providing a limited picture of the cancer burden caused by excess body weight. Apart from that, two other European studies $[19,20]$ have estimated overweight-attributable cancer incidence for Germany, but these used non-representative prevalence data and indirect cancer incidence estimates from the International Agency for Research on Cancer. The German Cancer Research Center (DKFZ) recently published an article about the cancer burden of overweight and obesity in Germany [21]. Their results correspond generally to our estimates. For some cancer types their results are somewhat lower, due to differences in the reference exposure category and relative risks.

To obtain more precise estimates taking into account a realistic latency period between risk factor exposition and cancer diagnosis, we estimated the cancer incidence attributable to overweight/obesity in Germany in 2010 for 13 different cancer types using representative prevalence data on excess body weight from a nationwide survey from 1998, national estimates of cancer incidence from German cancer registries as well as relative risk estimates from published meta-analyses. We evaluated three counterfactual scenarios: reduction of all BMI above 21 to $21 \mathrm{~kg} / \mathrm{m}^{2}$ as well as weight reductions among overweight or obese persons of 5 and $10 \%$. The latter two scenarios were chosen in order to evaluate more realistic goals for the reduction of excess body weight in Germany.

\section{Material and Methods}

Analyses of population-attributable risks (PARs) are based on the assumption of a causal relationship between the exposure (excess body weight) and outcome (cancer). Therefore, PARs were calculated for cancer types for which the International Agency for Research on Cancer (IARC) deemed an association with overweight/obesity to be convincing $[1,2]$. The following cancer types were included (according to ICD-10 classification): oesophagus ( $\mathrm{C} 15$, only adenocarcinoma; morphology codes see table 1$)$, gastric cardia (C16.0), colon (C18), rectum (C19-C20), liver (C22), gallbladder (C23), pancreas (C25), postmenopausal breast (C50), endometrium (C54-C55), ovary (C56), kidney (C64), thyroid (C73) and multiple myeloma (C90). Calcula- 
Wienecke et al.: Cancers Potentially Preventable through Excess Weight Reduction in Germany in 2010

Table 1. Summary risk estimates per $5 \mathrm{~kg} / \mathrm{m}^{2}$ increase in BMI by cancer sites and sex obtained from metaanalyses [27-30]

\begin{tabular}{|c|c|c|c|c|}
\hline \multirow[t]{2}{*}{ Cancer type } & \multicolumn{2}{|l|}{ Men } & \multicolumn{2}{|l|}{ Women } \\
\hline & $\begin{array}{l}\text { no. of included } \\
\text { studies }\end{array}$ & $\mathrm{RR}^{*}(95 \% \mathrm{CI})$ & $\begin{array}{l}\text { no. of included } \\
\text { studies }\end{array}$ & $\mathrm{RR}^{*}(95 \% \mathrm{CI})$ \\
\hline Oesophageal adenocarcinoma ${ }^{\S}$ & 5 & $1.52(1.33-1.74)$ & 3 & $1.51(1.30-1.74)$ \\
\hline Gastric cardia & 7 & $1.32(1.07-1.64)$ & 7 & $1.32(1.07-1.64)$ \\
\hline Colon & 24 & $1.30(1.25-1.36)$ & 20 & $1.12(1.06-1.17)$ \\
\hline Rectum & 17 & $1.09(1.06-1.13)$ & 14 & $1.02(0.99-1.05)$ \\
\hline Liver & 19 & $1.37(1.23-1.53)$ & 19 & $1.37(1.23-1.53)$ \\
\hline Gallbladder & 12 & $1.09(1.03-1.15)$ & 12 & $1.09(1.03-1.15)$ \\
\hline Pancreas & 14 & $1.13(1.04-1.22)$ & 15 & $1.10(1.04-1.16)$ \\
\hline Breast (postmenopausal) & - & - & 29 & $1.13(1.09-1.17)$ \\
\hline Endometrium & - & - & 28 & $1.54(1.47-1.61)$ \\
\hline Ovary & - & - & 24 & $1.08(1.04-1.12)$ \\
\hline Kidney & 9 & $1.24(1.17-1.32)$ & 10 & $1.33(1.25-1.42)$ \\
\hline Thyroid & 4 & $1.32(1.04-1.59)$ & 3 & $1.14(1.05-1.22)$ \\
\hline Multiple myeloma & 7 & $1.12(1.06-1.18)$ & 6 & $1.11(1.08-1.15)$ \\
\hline
\end{tabular}

No. $=$ Number; $\mathrm{RR}=$ relative risk; $\mathrm{CI}=$ confidence interval.

*per $5 \mathrm{~kg} / \mathrm{m}^{2}$ increase in BMI.

§Morphology codes: 8140-8141, 8143-8145, 8190-8231, 8260-8263, 8310, 8401, 8480-8490, 8550$8551,8570-8574,8576$ [53].

tions required information from three sources: i) the distribution of BMI in 1998 from a national, representative survey of adults in Germany, ii) cancer incidence rates for 2010 estimated from German cancer registry data and iii) risk estimates for the association between BMI and the included cancer types. PARs were calculated for men and women $\geq 35$ years of age living in Germany in the year 2010 .

\section{Distribution of BMI in Germany}

The distribution of BMI in the German population was obtained from the German National Health Interview and Examination Survey conducted by the Robert Koch Institute between 1997 and 1999 (GNHIES98). The study methods have been fully reported elsewhere [22, 23]. Briefly, the survey, which is conducted approximately every 10 years, covered a nationwide sample of the population in Germany aged 18-79 years and aimed to describe the health status and health behaviour of adults living in Germany. A total of 7,124 people took part in examinations and/or completed a validated questionnaire about relevant health issues. Anthropometric measurements were conducted by trained staff according to a standardized procedure with calibrated instruments. The current analyses refer to subjects $\geq 23$ years old who took part in the examinations ( $\mathrm{n}=5,931)$. BMI was calculated as weight in kilograms divided by height in meters squared $\left(\mathrm{kg} / \mathrm{m}^{2}\right)$. We mapped the distribution of BMI from the GNHIES98 survey to cancer incidence in 2010 to emulate the average follow-up time of 12 years in the prospective studies included in the selected meta-analyses (e.g. [24]). To achieve this, we added 12 years to the age at assessment of GNHIES98 participants. Furthermore, participants identified as having died through the end of December 2009 [25] were excluded from calculations.

\section{Cancer Incidence in Germany}

Cancer incidence in Germany for the year 2010 was obtained from estimates by the German Centre for Cancer Registry Data at the Robert Koch Institute. These annual national incidence calculations depend on the estimated completeness of each registry in the network providing nationwide coverage since 2009. Completeness estimates are based on mortality/incidence ratios and well established registries fulfilling defined quality criteria as a reference region [26]. For 2010 the estimated total number of incident cancer cases of 489,976 are based on 461,808 notified cases transmitted by the registries through the end of 2015 . Age-, sex- and site-specific incidence rates were estimated using these data. PARs were calculated for the 13 
Wienecke et al.: Cancers Potentially Preventable through Excess Weight Reduction in Germany in 2010

cancer types mentioned above. In 2010 there were an estimated 201,511 incident cases of the considered cancer types in the German population aged $\geq 35$ years.

Regular incidence estimates for Germany are generally limited to 3-digit ICD-10 codes. Figures for oesophageal adenocarcinoma and gastric cardia tumours were calculated using age- and sex-specific proportions of these tumours among all registered oesophageal and gastric tumours in regions with registration completeness $\geq 90 \%$. Furthermore, menopausal status at diagnosis is not indicated in the available cancer registry data. Therefore, we defined all breast cancer cases before the age of 50 years as premenopausal and all others as postmenopausal.

\section{Relative Risks}

Relative Risk (RR) estimates concerning the association between overweight/obesity and each cancer type were derived from meta-analyses [27-30]. The meta-analyses were identified via PubMed using the following MeSH-terms: (overweight OR obesity) AND (oesophageal/gastric/colorectal/liver/gallbladder/ pancreas/breast/endometrial/ovary/kidney/thyroid/multiple myeloma cancer OR neoplasm) AND metaanalysis. The search was limited to human studies as well as to papers written in English or German. To assess the quality of the identified meta-analyses, we used the AMSTAR-Score [31], a tool to assess the methodological quality of systematic reviews by an 11-item questionnaire. Meta-analyses were eligible for selection if they reported risk estimates for incident cancer with BMI as a continuous variable and included only prospective observational studies predominantly from Europe and North America. If more than one metaanalysis was eligible, the one deemed of best quality according to the AMSTAR-Score was selected. Table 1 displays the number of included studies in the selected meta-analyses and the RRs used to calculate the PARs.

\section{Statistical Analysis}

PARs were calculated according to the method of Tseng et al. [32], which is based on the formula from Bruzzi et al [33]. The original formula from Bruzzi et al. [33] requires knowledge of the risk factor distribution among cases. The method described by Tseng et al. [32] can be used to estimate this based on population-wide risk factor prevalence, e.g. based on representative surveys, combined with adjusted RR estimates and incidence data.

The original PAR formula from Bruzzi et al. [33] and the method from Tseng et al. [32] both assume a categorical risk factor. Since the categorization of BMI can lead to spurious results [34], we extended the previously published methods to accommodate a continuous-scale risk factor by replacing instances of summation with integration. Specifically, the equation by Tseng et al. [32] to determine the BMI-adjusted RR for age group $j\left(\mathrm{RR}_{* \mathrm{j}}\right.$ for age groups 35-44, 45-54, 55-64, 65-74 and 75+ years) was changed from

$$
R R_{* j}=\frac{R_{(w) j} \cdot p_{. j}}{R_{(w) 0} \cdot p_{.0}} \cdot\left[\frac{\sum_{i=0}^{k} p_{i 0} \cdot R R_{i *}}{\sum_{i=0}^{k} p_{i j} \cdot R R_{i *}}\right]
$$

to

$$
R R_{* j}=\frac{R_{(w) j} \cdot p_{. j}}{R_{(w) 0} \cdot p_{.0}} \cdot\left[\frac{\int_{0}^{\infty} d B C C G(x)_{0} \cdot R R(x) d x}{\int_{0}^{\infty} d B C C G(x)_{j} \cdot R R(x) d x}\right]
$$

where $R_{(w) j}$ is the age group-specific incidence rate; $p_{. j}$ is the proportion of the population in age group $j$; $\mathrm{RR}(\mathrm{x})$ is the confounder-adjusted RR at a BMI of $\mathrm{x}$; $\operatorname{dBCCG}(\mathrm{x})_{\mathrm{j}}$ is the density of the age group-and sex-specific, 3-parameter Box-Cox Cole and Green model, fitted to the GNHIES98 survey data using the gamlss package for R [35] at a BMI of x; and dx indicates integration over BMI. Equation 2 from Tseng et al. [32] was changed from

$$
p_{(c) i}=\frac{\sum_{j=0}^{l} R R_{i j} \cdot p_{i j}}{\sum_{i=0}^{k} \sum_{j=0}^{l} R R_{i j} \cdot p_{i j}}
$$

to

$$
p_{(c) i}=\frac{\sum_{j=0}^{l} R R_{* j} \cdot R R(x) \cdot d B C C G(x)_{j}}{\sum_{j=0}^{l} \int_{0}^{\infty} R R_{* j} \cdot R R(x) \cdot d B C C G(x)_{j} d x}
$$

where $\mathrm{p}(\mathrm{c})_{\mathrm{i}}$ is the proportion of cases exposed at a BMI of $\mathrm{x}$ and other parameters are as described above. Finally, Equation 1 was changed from 
Wienecke et al.: Cancers Potentially Preventable through Excess Weight Reduction in Germany in 2010

$$
P A R=1-\sum_{i=0}^{k} \frac{p_{(c) i}}{R R_{i *}}
$$

to

$$
P A R=1-\int_{0}^{\infty} \frac{p_{(c) i}}{R R(x)} d x
$$

To determine $\operatorname{RR}(\mathrm{x})$, the following algorithm was used: for BMI $\leq 21 \mathrm{~kg} / \mathrm{m}^{2}$, RR was defined as 1 . For BMI between 21 and $40 \mathrm{~kg} / \mathrm{m}^{2}$, the cancer-specific RR per unit increase in BMI (rr) was raised to the power of (BMI - 21). For all BMI of 40 and above, the RR at a BMI of 40 was used. Thus, a BMI of $21 \mathrm{~kg} / \mathrm{m}^{2}$ and below was considered to confer zero excess cancer risk, and risk did not continue to increase above a BMI of 40 $\mathrm{kg} / \mathrm{m}^{2}$ :

$$
R R(x)=\left\{\begin{array}{lr}
1, & x \leq 21 \\
r r^{x-21}, & 21<x<40 \\
r r^{19}, & x \geq 40
\end{array}\right.
$$

Separate PARs were calculated for each of three counterfactual scenarios. For the first counterfactual scenario (main analysis), we calculated PARs based on a weight reduction for all individuals with a BMI > 21 $\mathrm{kg} / \mathrm{m}^{2}$ to a value of $21 \mathrm{~kg} / \mathrm{m}^{2}$. For the two additional scenarios, we calculated PARs based on weight reductions of $5 \%$ and $10 \%$ among overweight and obese persons (i.e., BMI $\geq 25 \mathrm{~kg} / \mathrm{m}^{2}$ ). The two latter scenarios reflect the magnitude of weight reduction recommended by the WHO in order to help prevent overweightrelated diseases [1].

To examine how uncertainty in the RRs and survey data could affect PAR estimates, we conducted simulation analyses with 5,000 repetitions. RR estimates were sampled assuming independent log-normal distributions based on the published point estimates and the standard errors derived from published 95\% confidence intervals (95\% CI). Due to the complex sampling design of the surveys, a fully appropriate resampling technique with which we could incorporate uncertainty in the risk factor distribution was not identified. Instead, we sampled from the multivariate normal distribution of parameters from the fitted 3-parameter Box-Cox Cole and Green model to obtain simulated risk factor distributions. We present the 2.5th and 97.5th percentile PAR estimates calculated with these simulated relative risks and risk factor prevalence for our main analysis.

\section{Results}

Risk factor prevalence for the years 1997-1999 are based on data from 2,798 men and 3,133 women from the GNHIES98 survey, with a weighted average age at interview of $44.2 \pm$ 0.3 (mean \pm SE) and $47.0 \pm 0.3$ years, respectively. The mean BMI was $27.1 \pm 0.1 \mathrm{~kg} / \mathrm{m}^{2}$ for men and $26.6 \pm 0.1 \mathrm{~kg} / \mathrm{m}^{2}$ for women. Among men, $50.3 \%$ were overweight and $19.3 \%$ obese, whereas $31.1 \%$ of women were overweight and $23.0 \%$ obese. About $93.2 \%$ of men and women had a BMI $>21 \mathrm{~kg} / \mathrm{m}^{2}$. Table 2 gives an overview of the BMI distribution in the German population according to sex and age group.

Table 3 provides the PAR estimates for 2010 by cancer type for the main analysis. Overall, $10.5 \%$ of all new cancer cases in 2010 among women and $6.7 \%$ among men can be attributed to excess body weight, corresponding to 23,654 and 17,094 cases, respectively. Among women, PAR was highest for endometrial cancer with 48.1\% (95\% CI 43.8-52.2\%) and oesophageal adenocarcinoma with 47.8\% (95\% CI 32.7-60.0\%) followed by kidney $(34.4 \%$; 95\% CI 27.5-40.7\%) and gastric cardia cancer (34.4\%; 95\% CI 8.7-54.4\%). Among men, $45.7 \%$ (95\% CI 33.1-56.8\%) of oesophageal adenocarcinomas, 36.9\% (95\% CI 25.2-46.8\%) of liver cancer, $32.8 \%$ (95\% CI 8.6-51.8\%) of gastric cardia cancer and 31.6\% (95\% CI 27.0$35.9 \%$ ) of colon cancer were attributable to excess body weight. Overall, 40,748 new cancer cases in 2010 were attributable to overweight and obesity $-8.5 \%$ of all new cases that year. 

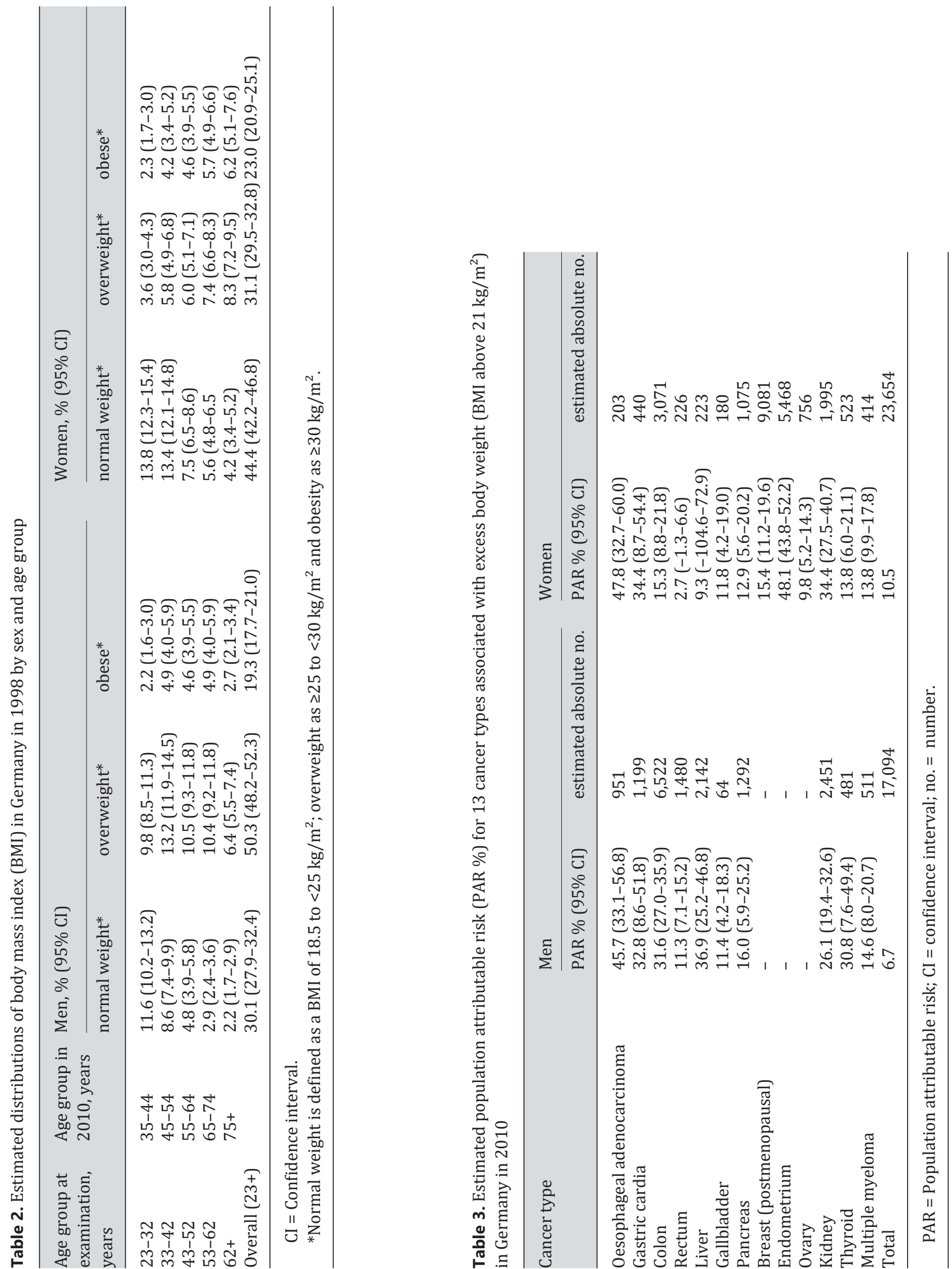
Wienecke et al.: Cancers Potentially Preventable through Excess Weight Reduction in Germany in 2010

Table 4. Estimated population attributable risk (PAR \%) for 13 cancer types after $5 \%$ and $10 \%$ reduction in weight among overweight and obese people in Germany in 2010

\begin{tabular}{|c|c|c|c|c|c|c|c|c|}
\hline \multirow[t]{3}{*}{ Cancer type } & \multicolumn{4}{|c|}{$5 \%$ weight reduction } & \multicolumn{4}{|c|}{$10 \%$ weight reduction } \\
\hline & \multicolumn{2}{|l|}{ men } & \multicolumn{2}{|l|}{ women } & \multicolumn{2}{|l|}{ men } & \multicolumn{2}{|l|}{ women } \\
\hline & PAR \% & Est. abs. no. & PAR \% & Est. abs. no. & PAR \% & $\begin{array}{l}\text { Est. abs. } \\
\text { no. }\end{array}$ & PAR \% & Est. abs. no. \\
\hline Oesophageal adenocarcinoma & 6.0 & 125 & 5.3 & 23 & 12.5 & 260 & 11.2 & 48 \\
\hline Gastric cardia & 4.7 & 172 & 4.3 & 55 & 9.7 & 355 & 8.8 & 112 \\
\hline Colon & 4.6 & 949 & 2.1 & 422 & 9.4 & 1940 & 4.3 & 863 \\
\hline Rectum & 1.8 & 236 & 0.4 & 33 & 3.6 & 471 & 0.8 & 67 \\
\hline Liver & 5.2 & 302 & 1.3 & 31 & 10.6 & 615 & 2.7 & 65 \\
\hline Gallbladder & 1.8 & 10 & 1.7 & 26 & 3.7 & 21 & 3.4 & 52 \\
\hline Pancreas & 2.5 & 204 & 1.8 & 150 & 5.0 & 409 & 3.7 & 308 \\
\hline Breast (postmenopausal) & - & - & 2.1 & 1,238 & - & - & 4.3 & 2,535 \\
\hline Endometrium & - & - & 5.3 & 602 & - & - & 11.2 & 1,273 \\
\hline Ovary & - & - & 1.4 & 108 & - & - & 2.8 & 216 \\
\hline Kidney & 3.9 & 366 & 4.2 & 244 & 7.9 & 742 & 8.8 & 510 \\
\hline Thyroid & 4.5 & 70 & 1.8 & 68 & 9.1 & 142 & 3.7 & 140 \\
\hline Multiple myeloma & 2.3 & 81 & 1.9 & 57 & 4.7 & 165 & 3.9 & 117 \\
\hline Total & 1.0 & 2,515 & 1.4 & 3,057 & 2.0 & 5,120 & 2.8 & 6,307 \\
\hline
\end{tabular}

PAR = Population attributable risk; Est. abs. no. = estimated absolute numbers.

With a PAR of $15.4 \%$ (95\% CI 11.2-19.6\%), 9,081 cases of postmenopausal breast cancer were attributable to overweight and obesity. With 8,002 cases, colorectal cancer accounted for the highest absolute number of attributable cases among men.

The two additional counterfactual scenarios revealed that, if weight could be reduced by $5 \%$ or $10 \%$ among overweight and obese persons, the mean BMI would shift from 26.8 $\mathrm{kg} / \mathrm{m}^{2}$ to $25.9 \mathrm{~kg} / \mathrm{m}^{2}$ and $25.0 \mathrm{~kg} / \mathrm{m}^{2}$ respectively. An estimated 5,572 cancer cases $(5 \%$ weight reduction) or 11,427 cases (10\% weight reduction) could be prevented in the German population aged $\geq 35$ years. This corresponds to $1.2 \%$ or $2.4 \%$ of all new cancer cases in 2010 (table 4). The PAR estimates for a $10 \%$ weight reduction are three to four times smaller than the PARs for the main analysis.

\section{Discussion}

Our analyses indicate that about 9\% of all new cancer cases in 2010 among adults in Germany aged $\geq 35$ years were attributable to excess body weight. This corresponds to 40,750 cases that might have been preventable had BMI in the population 12 years prior not exceeded $21 \mathrm{~kg} / \mathrm{m}^{2}$. Postmenopausal breast, endometrial and colon cancer accounted for $75 \%$ of the total attributable cases among women, whereas colon, kidney and liver cancer accounted for $65 \%$ among men. Women seem to have a higher overall PAR, with $10.5 \%$ versus $6.7 \%$ among men. The higher PAR and attributable cases among women are likely due to postmenopausal breast, endometrial and ovarian cancers, which are strongly associated with excess body weight. Other studies investigating BMI and cancer incidence also estimated an overall PAR for women nearly twice as high as for men [20,36]. Hence, excess body weight seems to be a greater issue for women than for men regarding cancer, while other risk factors like tobacco or alcohol consumption seem to have the greatest influence among men. 
The counterfactual scenarios involving weight reductions of 5\% and 10\% among overweight and obese persons revealed that these more modest weight reductions could have prevented 5,572 or 11,427 cancer cases $(1.2 \%$ or $2.4 \%$ of all new cancer cases) in 2010 . These are probably more realistic estimates of the preventable proportion of the current cancer burden due to excess body weight than assuming a theoretical cap of BMI at $21 \mathrm{~kg} / \mathrm{m}^{2}$. To achieve a maximum BMI of $21 \mathrm{~kg} / \mathrm{m}^{2}$ in the German population, men and women who had a BMI above $21 \mathrm{~kg} / \mathrm{m}^{2}$ at the time of the GNHIES98 survey would have had to reduce their weight on average by $21 \%$. Instead, the prevalence of obesity in Germany since then has generally increased, predominantly among young adults [12, 37]. Therefore, measures to reduce or prevent further increases in BMI are relevant for Germany, and young men and women appear to be a population group at higher risk.

In comparisons with other studies, our PAR estimates show both similarities as well as some considerable differences. The World Cancer Research Fund published estimates in 2009 for the UK and the US that are very similar to our estimates [38]. Renehan and colleagues [20] published estimates for Europe in 2010 that are much lower than our estimates, especially for those cancer types for which we estimated a high PAR (oesophageal, endometrial and renal cancer). These differences might be due to different BMI distributions in the populations as Renehan and colleagues [20] used data on prevalence of excess body weight from the WHO Global Infobase and on cancer incidence from GLOBOCAN 2002. Lehnert and colleagues [18] estimated population-attributable fractions for cancer mortality in the German population using BMI prevalence data from the German Health Interview and Examination Survey (DEGS1) and the German Study on Ageing, Cognition and Dementia in Primary Care Patients (AgeCoDe) and RR estimates from a cohort study of US adults. Their estimates are considerably lower for oesophageal, gastric, cervix uteri and kidney cancer but largely the same for the other cancer types. As noted, however, those investigators addressed cancer mortality as opposed to incidence, which hampers a direct comparison of these PAR estimates.

Tobacco and alcohol consumption have large detrimental effects on population health, including large PARs for lung, laryngeal and renal cancers $[39,40]$. Previous estimates for the German adult population, using methods similar to those used here, showed that tobacco has the greatest PAR for organs of the upper aerodigestive tract (UADT) [39]. Alcohol showed a smaller overall PAR by itself, but high PARs were seen for cancers of the UADT in combination with tobacco [40]. Table 5 provides an overview of PAR estimates for these risk factors regarding cancer types affected by excess body weight. For some common cancer sites (colonrectum, liver, breast and endometrium) overweight and obesity account for more cases than tobacco or alcohol consumption. Regarding men, the PAR for colorectal cancer is about $10 \%$ for both tobacco and alcohol, whereas the PAR for excess body weight is $24 \%$. Concerning breast cancer among women aged 35 years and older, the PAR for overweight/obesity is nearly twice as high as for alcohol (13 vs. 7\%). Overweight and obesity should therefore not be underestimated as cancer risk factors, especially considering the increasing obesity prevalence and decreasing tobacco and alcohol consumption in Germany and in other countries.

\section{Limitations and Strengths}

The present analysis has a number of limitations. First, BMI might not always be an accurate measure for general adiposity and excess body weight, as it does not differentiate between body fat and fat-free mass. Waist-to-hip ratio (WHR) and waist circumference (WC) are alternative measures of excess body weight, but recent studies showed only limited evidence that WHR or WC are better predictors of cancer risk than BMI [8]. Thus, we used BMI as an approximation of general adiposity as it is an accepted indicator for and the most widely used measure of the degree of overweight and obesity [1]. 
Wienecke et al.: Cancers Potentially Preventable through Excess Weight Reduction in Germany in 2010

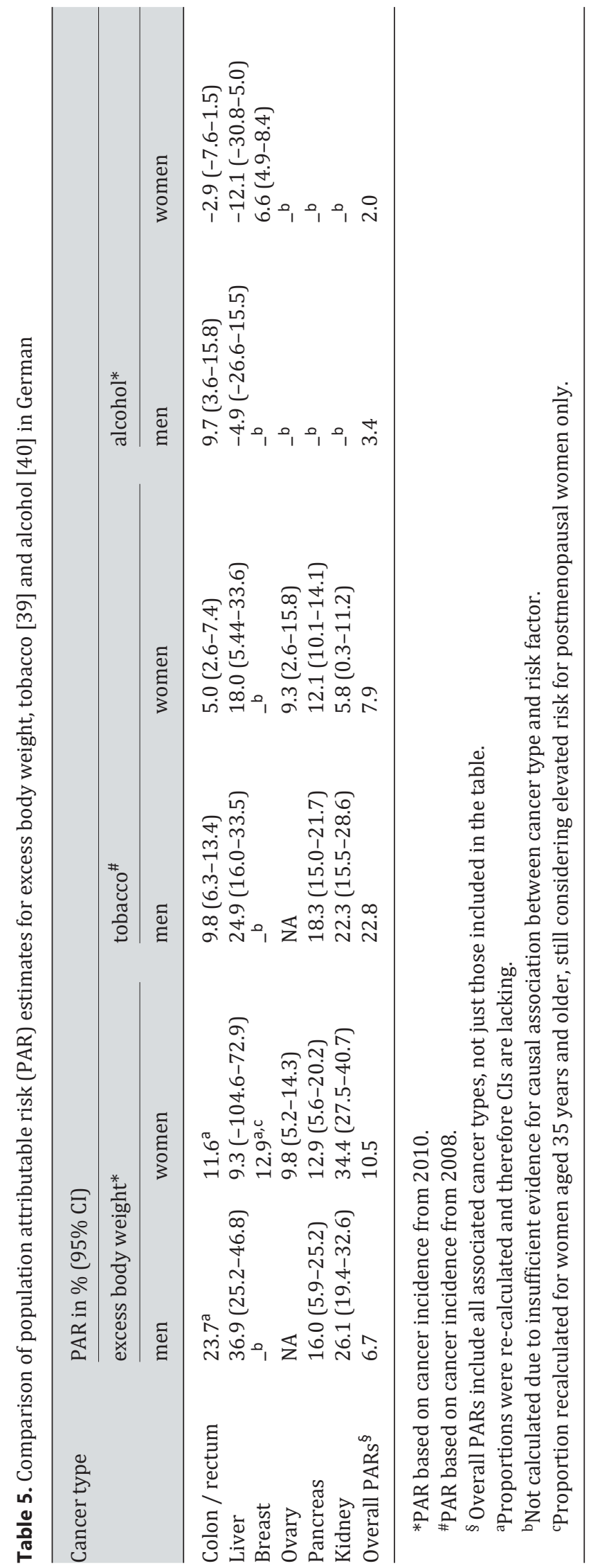


Wienecke et al.: Cancers Potentially Preventable through Excess Weight Reduction in Germany in 2010

A second limitation is the use of BMI from one time point. At least for colorectal and postmenopausal breast cancer, (large) weight gain in adulthood increases cancer risk and dynamic weight change seems to be a more sensitive indicator of adiposity than BMI measured at one point in time [41, 42].

Third, in calculating PAR for postmenopausal breast cancer, age was used as a proxy for menopausal status as we lacked any data on menopausal status at diagnosis in the cancer registry data. Other analyses have obtained consistent estimates when comparing clinically defined menopausal status with an aged-based cut-off [43].

Fourth, the decision that a BMI of $21 \mathrm{~kg} / \mathrm{m}^{2}$ confers zero excess risk may be arbitrary and might only be of theoretical value. However, it reflects the population BMI recommended by the World Health Organization for achieving lowest weight-related health risks [44]. Furthermore, there seems to be no excess cancer mortality risk for underweight persons $\left(\mathrm{BMI}<18 \mathrm{~kg} / \mathrm{m}^{2}\right)$ [45]. In Germany, only $2.3 \%$ of women and $0.7 \%$ of men are underweight.

Fifth, PARs were calculated with the general assumptions that BMI directly causes cancer and that reducing BMI reduces cancer risk. Although based on observational studies, various meta-analyses and reviews have demonstrated a positive association between cancer risk and BMI $[29,41,43,46]$. In addition, plausible biological mechanisms linking overweight and obesity with carcinogenesis have been identified $[7,8]$. The weight of this evidence sufficed to deem the association convincing [1-3]. Nevertheless, it remains unknown whether effective interventions to decrease body weight in adult populations will reduce cancer incidence [43]. Some support for the effectiveness of interventions comes from prospective cohorts investigating intentional weight loss and cancer risk [47, 48], as well as from findings of reduced cancer incidence after bariatric surgery in morbidly obese patients [49].

Sixth, nationwide obesity prevalence data based on anthropometric measurements are only recorded about every 10 years in Germany. Under consideration of a 12-year lag time between BMI measurement and cancer incidence, the most recent prevalence data come from 1998, corresponding to cancer incidence in 2010.

Finally, there are indications for associations between excess body weight and cancer types that were not considered in the present estimates, such as aggressive prostate cancer or male breast cancer [2]. Thus, our results may have underestimated the full impact of excess body weight on cancer incidence.

To our knowledge, this is the first study quantifying the preventable proportion of the incidence of 13 different cancer types attributable to excess body weight in Germany under multiple counterfactual scenarios using age- and sex-specific BMI estimates from a nationwide survey as well as cancer incidence from German cancer registries. These aspects allow representative PAR estimates for the German population. Moreover, height and weight were measured in a standardized way, thereby increasing accuracy and consistency compared to self-reported data. From a public health perspective, the focus on incident cases allows a more complete view of the cancer burden caused by excess body weight than a focus on cancer mortality. Preventing cancer incidence not only prevents cancer death but also prevents the loss of quality of life as well as the increased health care resources that go along with a cancer diagnosis.

The two additional counterfactual scenarios illustrate the impact of weight reduction by simulating a shift of the BMI distribution from a mean of $27 \mathrm{~kg} / \mathrm{m}^{2}$ to a mean of $26 \mathrm{~kg} / \mathrm{m}^{2}$ (5\% reduction) or $25 \mathrm{~kg} / \mathrm{m}^{2}$ (10\% reduction). These likely reflect more realistic scenarios than assuming a theoretical minimum risk with a maximum BMI of $21 \mathrm{~kg} / \mathrm{m}^{2}$. However, even the BMI achieved with a $10 \%$ reduction among overweight and obese people, would still lie above the range of population average BMI recommended by the WHO [44].

Despite the weight reduction recommendations of the WHO, there is little evidence thus far of progress in the German population. In fact, BMI has increased over recent decades 
Wienecke et al.: Cancers Potentially Preventable through Excess Weight Reduction in Germany in 2010

among adults $[12,37]$ as well as among children, the latter having plateaued at a high level in recent years $[50,51]$. Due to the potentially long delay before weight-related cancer develops, the burden of cancer associated with excess body weight is likely to grow further. The increasing rates of overweight-associated oesophageal adenocarcinoma in the last 20 years in various western societies, compared to decreasing rates of tobacco- and alcohol-related oesophageal squamous cell carcinoma $[52,53]$, indicate the growing importance of excess body weight.

\section{Conclusions}

In Germany there is a considerable preventive potential regarding cancers associated with excess body weight. For some cancers, the proportion attributable to excess body weight, measured as BMI, exceeds that attributable to tobacco or alcohol consumption. Even a modest weight reduction of 5\% in overweight and obese persons might prevent over 5,000 cases per year. In light of increasing BMI and decreasing tobacco and alcohol consumption in the German population, both the absolute and the relative impact of overweight and obesity on cancer incidence is increasing. Efforts to prevent weight gain and encourage weight loss for overweight and obese persons at all ages should be promoted.

\section{Acknowledgements}

The authors thank all the German cancer registries as well as the teams of the German health survey at the Robert Koch Institute for providing the comprehensive data sets.

\section{Disclosure Statement}

The authors declare that they have no conflicts of interest.

\section{References}

1 International Agency for Research on Cancer: Weight control and physical activity; in Vainio H, Bianchini F (eds): IARC Handbook of Cancer Prevention. Volume 6. Lyon, IARC Press, 2002, pp 1-315.

$\checkmark 2$ Lauby-Secretan B, Scoccianti C, Loomis D, Grosse Y, Bianchini F, Straif K; for the International Agency for Research on Cancer Handbook Working Group: Body fatness and cancer - viewpoint of the IRAC Working Group. N Eng J Med 2016;375:794-798.

3 World Cancer Research Fund, American Institute for Cancer Research: Food, Nutrition, Physical Activity and the Prevention of Cancer: A Global Perspective. Washington DC, World Cancer Research Fund / American Institute for Cancer Research, 2007.

4 Abdullah A, Peeters A, Courten Md, Stoelwinder J: The magnitude of association between overweight and obesity and the risk of diabetes: a meta-analysis of prospective cohort studies. Diabetes Res Clin Pract 2010; 89:309-319.

-5 Bogers RP, MBemelmans WJ, Hoogenveen RT, Boshuizen HC, Woodward M, Knekt P, van Dam RM, Hu FB, Visscher TL, Menotti A, Thorpe RJ Jr, Jamrozik K, Calling S, Strand BH, Shipley MJ; BMI-CHD Collaboration Investigators: Association of overweight with increased risk of coronary heart disease partly independent of blood pressure and cholesterol levels: a meta-analysis of 21 cohort studies including more than 300000 persons. Arch Intern Med 2007;167:1720-1728.

-6 Emerging Risk Factors Collaboration, Wormser D, Kaptoge S, Di Angelantonio E, Wood AM, Pennells L, Thompson A, Sarwar N, Kizer JR, Lawlor DA, Nordestgaard BG, Ridker P, Salomaa V, Stevens J, Woodward M, Sattar N, Collins R, Thompson SG, Whitlock G, Danesh J.: Separate and combined associations of body-mass index and abdominal adiposity with cardiovascular disease: collaborative analysis of 58 prospective studies. Lancet 2011;377:1085-1095.

7 Louie SM, Roberts LS, Nomura DK: Mechanisms linking obesity and cancer. Biochim Biophys Acta 2013;1831: 1499-1508. 
Wienecke et al.: Cancers Potentially Preventable through Excess Weight Reduction in Germany in 2010

8 Renehan AG, Zwahlen M, Egger M: Adiposity and cancer risk: new mechanistic insights from epidemiology. Nat Rev Cancer 2015;15:484-498.

9 Lange C, Finger J: Health-related behaviour in Europe - a comparison of selected indicators for Germany and the European Union. J Health Monitoring 2017;2:3-19.

10 Gorber SC, Tremblay M, Moher D, Gorber B: A comparison of direct vs. self-report measures for assessing height. weight and body mass index: a systematic review. Obes Rev 2007;8:307-326.

11 Mensink GBM, Schienkiewitz A, Haftenberger M, Lampert T, Ziese T, Scheidt-Nave C: Overweight and obesity in Germany. Results of the German Health Interview and Examination Survey for Adults (DEGS1) (in German). Bundesgesundheitsbl Gesundheitsforsch Gesundheitssch 2013;56:786-794.

12 Finucane M, Stevens G, Cowan M, Danaei G, Lin JK, Paciorek CJ, Singh GM, Gutierrez HR, Lu Y, Bahalim AN, Farzadfar F, Riley LM, Ezzati M; Global Burden of Metabolic Risk Factors of Chronic Diseases Collaborating Group (Body Mass Index): National, regional, and global trends in body-mass index since 1980: systematic analysis of health examination surveys and epidemiological studies with 960 country-years and 9.1 million participants. Lancet 2011;377:557-567.

13 OECD, EC: Health at a Glance: Europe 2016. State of Health in the EU Cycle, 4th ed. Paris, OECD Publishing. 2016. www.oecd.org/health/health-at-a-glance-europe-23056088.htm (last accessed October 8, 2018).

14 Lange C, Manz K, Rommel A, Schienkiewitz A, Mensink GBM: Alcohol consumption of adults in Germany: harmful drinking quantities, consequences and measures. J Health Monitoring 2016;1:2-20.

15 Zeiher J, Kuntz B, Lange C: Smoking among adults in Germany. J Health Monitoring 2017;2:57-63.

16 Konnopka A, Bödemann M, König H-H: Health burden and costs of obesity and overweight in Germany. Eur J Health Econ 2011;12:345-352.

17 Lehnert T, Streltchenia P, Konnopka A, Riedel-Heller SG, König H-H: Health burden and costs of obesity and overweight in Germany: an update. Eur J Health Econ 2015;16:957-967.

18 Bergström A, Pisani P, Tenet V, Wolk A, Adami H-O: Overweight as an avoidable cause of cancer in Europe. Int J Cancer 2001;91:421-430.

19 Renehan AG, Soerjomataram I, Tyson M, Egger M, Zwahlen M, Coebergh JW, Buchan I: Incident cancer burden attributable to excess body mass index in 30 European countries. Int I Cancer 2010;126:692-702.

-20 Bellach B-M, Knopf H, Thefeld W: The German National Health Examination Survey 1997/1998. Gesundheitswesen 1998;60(suppl 2):S59-S68.

21 Behrens G, Gredner T, Stock C, Leitzmann MF, Brenner H, Mons U: Cancers due to excess weight, low physical activity, and unhealthy diet. Dtsch Arztebl Int 2018;115:578-585.

22 Bergmann KE, Mensink GBM: Anthropometric data and overweight (in German). Gesundheitswesen 1999; 61(suppl 2):S115-S120.

23 Renehan AG, Soerjomataram I, Leitzmann MF: Interpreting the epidemiological evidence linking obesity and cancer: a framework for population-attributable risk estimations in Europe. Eur J Cancer 2010;46:2581-2592.

-24 Wolf I-K, Busch M, Lange M, Kamtsiuris P, Doelle R, Richter A, Kuhnert R, Ziese T, Knopf H, Scheidt-Nave C: Mortalitäts-Follow-up der Studie zur Gesundheit Erwachsener in Deutschland (DEGS). Methodik und erste Ergebnisse. Bundesgesundheitsbl Gesundheitsforsch Gesundheitssch 2014;57:1331-1337.

25 Kraywinkel K, Barnes B, Dahm S, Haberland J, Nennecke A, Stabenow R: Nationwide statements from regional data. Methods of The Center for Cancer Registry Data (in German). Bundesgesundheitsbl Gesundheitsforsch Gesundheitssch 2014;57:13-21.

26 Aune D, Greenwood DC, Chan DSM, Vieira R, Vieira AR, Navarro Rosenblatt DA, Cade JE, Burley VJ, Norat T: Body mass index, abdominal fatness and pancreatic cancer risk: a systematic review and non-linear doseresponse meta-analysis of prospective studies. Ann Oncol 2012;23:843-852.

27 Chen Y, liu L, Wang X, Wang J, Yan Z, Cheng J, Gong G, Li G: Body mass index and risk of gastric cancer: a metaanalysis of a population with more than ten million from 24 prospective studies. Cancer Epidemiol Biomarkers Prev 2013;22:1395-1408.

28 Kyrgiou M, Kalliala I, Markozannes G, Gunter MJ, Paraskevaidis E, Gabra H, Martin-Hirsch P, Tsilidis KK: Adiposity and cancer at major anatomical sites: umbrella review of the literature. BMJ 2017;356:j477.

29 Park M, Song DY, Je Y, Lee JE: Body mass index and biliary tract disease: a systematic review and meta-analysis of prospective studies. Prev Med 2014;65:13-22.

-30 Shea BJ, Grimshaw JM, Wells GA, Boers M, Andersson N, Hamel C, Porter AC, Tugwell P, Moher D, Bouter LM: Development of AMSTAR: a measurement tool to assess the methodological quality of systematic reviews. BMC Med Res Methodol 2007;7:10.

-31 Tseng M, Weinberg CR, Umbach DM, Longnecker MP: Calculation of population attributable risk for alcohol and breast cancer (United States). Cancer Causes Control 1999;10:119-123.

-32 Bruzzi P, Green SB, Byar DP, Brinton LA, Schairer C: Estimating the population attributable risk for multiple risk factors using case-control data. Am J Epidemiol 1985;122:904-914.

-33 Barendregt JJ, Veerman JL: Categorical versus continuous risk factors and the calculation of potential impact fractions. J Epidemiol Community Health 2010;64:209-212.

-34 Rigby R, Stasinopoulos D: Generalized additive models for location, scale and shape (with discussion). Appl Stat 2005;54:507-554.

- 35 Arnold M, Pandeya N, Byrnes G, Renehan AG, Stevens G, Ezzati M, Ferlay J, Miranda JJ, Romieu I, Dikshit R, Forman D, Soerjomataram I: Global burden of cancer attributable to high body-mass index in 2012:a population-based study. Lancet Oncol 2015;16:36-46. 
Wienecke et al:: Cancers Potentially Preventable through Excess Weight Reduction in Germany in 2010

-36 Finger J, Busch M, Du Y, Heidemann C, Knopf H, Kuhnert R, Lampert T, Mensink GBM, Neuhauser H, SchaffrathRosario A, Scheidt-Nave C, Schienkiewitz A, Truthmann J, Kurth BM: Timer trends in cardiometabolic risk factors in adults - results from three nationwide German examination surveys from 1990-2011. Dtsch Arztebl Intern 2016;113:712-719.

37 World Cancer Research Fund / American Institute for Cancer Research: Policy and Action for Cancer Prevention. Food, Nutrition and Physical Activity: A Global Perspective. Washington DC, American Institute for Cancer Research, 2009. www.wcrf.org/sites/default/files/Policy_Report.pdf (last accessed October 8, 2018).

38 Wienecke A, Barnes B, Lampert T, Kraywinkel K: Changes in cancer incidence attributable to tobacco smoking in Germany, 1999-2008. Int J Cancer 2014;134:682-691.

-39 Wienecke A, Barnes B, Neuhauser H, Kraywinkel K: Incident cancers attributable to alcohol consumptions in Germany, 2010. Cancer Causes Control 2015;26:903-911.

-40 Boeing H: Obesity and cancer - the update 2013. Best Pract Res Clin Endocrinol Metabol 2013;27:219-227.

-41 Schlesinger S, Lieb W, Koch M, Fedirko V, Dahm CC, Pischon T, Nöthlings U, Boeing H: Body weight gain and risk of colorectal cancer: a systematic review and meta-analysis of observational studies. Obes Rev 2015;16: 607-619.

-42 Renehan AG, Tyson M, Egger M, Heller RF, Zwahlen M: Body-mass index and incidence of cancer: a systematic review and meta-analysis of prospective observational studies. Lancet 2008;371:569-578.

43 James WPT, Jackson-Leach R, Ni Mhurchu C, Kalamara E, Shayeghi M, Rigby NJ, Nishida C, Rodgers A: Overweight and obesity (high body mass index); in Ezzati M, Lopez AD, Rodgers A, et al (eds): Comparative Quantification of Health Risks Global and Regional Burden of Disease Attributable to Selected Major Risk Factors. Geneva, World Health Organization, 2004.

44 Flegal KM, Graubard BI, Williamson DF, Gail MH: Cause-specific excess death associated with underweight, overweight and obesity. JAMA 2007;298:2028-2037.

45 Calle E, Kaaks R: Overweight, obesity and cancer: epidemiological evidence and proposed mechanisms. Nat Rev Cancer 2004;4:579-591.

-46 Parker ED, Folsom AR: Intentional weight loss and incidence of obesity-related cancers: the Women's Health Study. Int J Obes Relat Metab Disord 2003;27:1447-1452.

-47 Rodriguez C, Freedland SJ, Deka A, Jacobs EJ, McCullough ML, Patel AV, Thun MJ, Calle E: Body mass index, weight change, and risk of prostate cancer in the Cancer Prevention Study II Nutrition Cohort. Cancer Epidemiol Biomarkers Prev 2007;16:63-69.

48 Renehan AG: Bariatric surgery, weight reduction and cancer prevention. Lancet Oncol 2009;10:640-641.

-49 Brettschneider A-K, Schaffrath-Rosario A, Kuhnert R, Schmidt S, Wiegand S, Ellert U, Kurth B-M: Updated prevalence rates of overweight and obesity in 11- to 17-year-old adolescents in Germany. Results from the telephone-based KiGGS Wave 1 after correction for bias in self-reports. BMC Public Health 2015;15:1101.

-50 Brettschneider A-K, Schienkiewitz A, Schmidt S, Ellert U, Kurth B-M: Updated prevalence rates of overweight and obesity in 4- to 10-year-old children in Germany. Results from the telephone-based KiGGS Wave 1 after correction for bias in parental reports. Eur J Pediatr 2017;176:547-551.

-51 Feller A, Fehr M, Bordoni A, Bouchardy C, Frick H, Mousavi M, Steiner A, Arndt V, Clough-Gorr K, NICER Working Group: Trends in incidence of oesophageal and gastric cancer according to morphology and anatomical location, in Switzerland 1982-2011. Swiss Med Weekly 2015;145:w14245.

52 Xie S-H, Mattsson F, Lagergren J: Incidence trends in oesophageal cancer by histological type: an uptdated analysis in Sweden. Cancer Epidemiol 2017;47:114-117.

53 Ferlay J, Rous B: Chapter 4: Histological groups; in Forman D, Bray F, Brewster D, Gombe Mbalawa C, Kohler B, Pineros M, Steliarova-Foucher E, Swaminathan R, Ferlay J (eds): Cancer Incidence in Five Continents, volume X. Lyon, International Agency for Research on Cancer, 2014. 